\title{
PAPER
}

\section{Sustainability and specialization}

\author{
John Cairns, Jr.* \\ Department of Biology, Virginia Polytechnic Institute and State University, Blacksburg, Virginia 24061, USA
}

\begin{abstract}
Society depends heavily on its major universities and independent research organizations for new ideas. Arguably, sustainable use of the planet will require conceptual paradigms unprecedented in human history. Educational systems, especially major universities and research organizations, must produce students in all phases of the education continuum who are capable of transdisciplinary activities. A much larger group of such students will be required to implement these new undertakings. Until the perception of the need for transdisciplinary education becomes widespread, nothing significant is likely to happen. One major obstacle is the lack of employment for transdisciplinary individuals. A commitment to sustainable use of the planet will provide employment and make better use of increasingly scarce resources.
\end{abstract}

KEY WORDS: Sustainability · Academic specialization · Educational system · Transdisciplinary · Data integration $\cdot$ Co-evolutionary process $\cdot$ Environmental education

Resale or republication not permitted without written consent of the publisher

When environmental ethicists create a separate, distinct discipline with its own terms and assumptions, they disqualify themselves as the integrative contributors they could be if their disciplines were built in public discourse, the rich, highly textured language upon which we fall back when we are faced with a crisis or problem and must decide collectively what to do about it.

Bryan G. Norton, 2003

This well-meaning but narrow-minded nanny of an institution ensures that scientists work according to conventional wisdom and not as curiosity or inspiration moves them. Lacking freedom they are in danger of succumbing to a finicky gentility or of becoming, like medieval theologians, the creatures of dogma.

James Lovelock, 2000

The ongoing fragmentation of knowledge and resulting chaos in philosophy are not reflections of the real world but artifacts of scholarship.

Edward O. Wilson, 1998

\section{INTEGRATION OF DATA}

Sustainable use of the planet is a policy goal that requires input from all disciplines, professions, and special interest groups. The disciplines are essential for academic quality control; however, if they remain in the present degree of isolation from each other, sustainability is unlikely to be achieved. The disciplines are the basic units of a bottom-up approach in which the components of sustainability are studied, but the top-down approach covers large temporal and spatial spans and is essential to the implementation of sustainability strategies. Specialization facilitates development of quality control practices for both data and personnel and is often referred to as the reductionist approach. The twentieth century was the age of specialization.

Integration of information and data is essential for the study of complex, multivariate systems. If sustainability is to be achieved effectively, integration of 
human society with all components of the planet's ecological life support system (i.e. both natural capital and ecosystem services) is mandatory. If humankind is fortunate, the twenty-first century will be known as the age of integrative knowledge and concepts.

\section{THE ROLE OF ACADEME}

The educational systems in the United States and elsewhere have made an exploratory effort toward integrating transdisciplinary data, but the effort may be too little, too late. After years of domination by specialization, adding a whole new structure will be extremely difficult, especially in a time of budgetary problems. In addition, the transformation to integrating transdisciplinary data must occur without impairing the integrity of the disciplines. Since major research universities are markedly dependent upon extramural funding, which is increasingly transdisciplinary, the rate of change will almost certainly be greater than if these universities were not so dependent upon outside funding.

In the United States, the amount of extramural funding is one of the most widely used ranking systems for universities. Naturally, ambitious administrators keep a vigilant eye upon those faculty who acquire major grants and contracts. Since some disciplines are more likely to acquire major extramural funding than others, each university experiences an imbalance as the more competitive disciplines are favored.

Inevitably, a division of the haves (well-funded) and the have-nots (little or no extramural funding) occurs. This imbalance can be diminished with endowment funds; however, a vast gulf which may negate cooperation may develop between the haves and the havenots. Such a gulf is not a favorable condition for the exceptionally broad, transdisciplinary projects required to achieve sustainable use of the planet. Arguably, this lack of substantive interaction between disciplines is the most aggravating obstacle to developing sound sustainability strategies. Presumably, the dissimilarities in funding just mentioned will lessen as funding for sustainability projects increases. Even so, this issue deserves more attention than it is now receiving.

Many corporate and government grants and contracts are for a specific purpose. This specificity is to be expected because corporations must answer to stockholders and much government money comes from agencies with a specific mission. As a consequence, sustainable transportation, sustainable cities, sustainable energy sources, and sustainable agriculture are the typical categories of grants; however, specific grants and/or contracts may fall within even narrower disciplinary scopes. Funds to integrate these dissimilar fields into a comprehensive global, national, or regional strategy are far below probable needs.

\section{CATASTROPHES}

Issues important to sustainability probably will not be given serious attention at a global level until a major catastrophe occurs. Even then, a global response may not occur if the event is restricted to one or two nation-states. Of course, some components of sustainability may be addressed because, even at present, the need for more sustainable practices is evident (e.g. water management) or because sustainable practices lower unit product cost for corporations (e.g. energy policy). In addition, the prospect of leaving a habitable planet for posterity and an increased compassion for other life forms are powerful ethical motives. Even in these instances, however, the need for sustainable practices is acknowledged more often than implemented.

In democratic societies, most politicians focus intently on re-election rather than on long-term strategies of any type. Since campaign costs are increasingly expensive and special-interest groups are a major source of funds, practicality motivates politicians to place emphasis on the interests of their contributors. However, if the general public gave responsibility for the well-being of posterity a high priority, these motivations could change rapidly. Lobbyists for specialinterest groups are specialists in promoting their interests. Some pose less danger than others if their activities are directed in the general context of sustainable use of the planet. After all, society includes a variety of special-interest groups and probably always will. The danger occurs when special interests replace, rather than supplement, broad ethical responsibilities.

\section{SPECIALIZATION}

Arguably, the most intense experience in specialization occurs in the academic community. In academe, especially in the sciences, a highly motivated, intelligent individual can, in a few years, generate specialized information about a narrow area that is new even to the august members of the graduate advisory or tenure and promotion committee. The lesson is unmistakable-generation of robust, specialized information is the key to early recognition from one's mentors and peers. This process is accompanied by rites of passage that confer recognition of accomplishment; these rites of passage may also act as isolating mechanisms. 
Specialized disciplinary terminology (an uncharitable person might use the word jargon) that is comprehensible only to a select group is another isolating mechanism used within the disciplines. International, national, and regional meetings of each discipline require use of this terminology to illustrate a specialist's knowledge of the field. Specialized terminology also isolates disciplines from each other since the terminology changes (i.e. addition of new terms) occur rapidly enough to require a significant effort to remain current. In academic institutions, promotion and tenure are dependent upon the recommendation of members of the disciplines to the college and/or university committee, which usually consists of still more disciplinary specialists.

I once collaborated for about a decade with an optical physicist, who specialized in laser holography, in developing a rapid biological information system based on species diversity (Almeida et al. 1978, Cairns et al. 1976). I never became an optical physicist and Sil Almeida never became a biologist, but we were able to communicate effectively to produce interdisciplinary research suitable for publication in peer-reviewed journals. This collaboration also provided valuable interdisciplinary experiences for graduate students and post-doctoral fellows. Finally, grant funding would not have been available to either discipline without the other. On the negative side, we were alienated from members of our own basic disciplines because both the terminology and the journals were unfamiliar to members of our disciplinary fields.

\section{LIMITATIONS OF THE HUMAN BRAIN}

Szent-Gyorgi (1962, p. 11) stated: 'Primarily the human brain is an organ of survival. It was built by nature to search for food, shelter, and the like, to gain advantage - before addressing itself to the pursuit of truth.' Heerwagen \& Orians (1993) comment on the suitabilityof the human brain for both analyzing and responding effectively to the conditions of ancestral environments. Society cannot reasonably expect the over 3 billion individuals living on US\$3/capita/day or less to spend any significant amount of time on sustainability when their primary concern is survival. On the other hand, for the more affluent, time remaining in a busy schedule is often used to achieve status.

Economist Kenneth Boulding (1956) asserted that, beyond a certain degree of complexity, the human mind substitutes symbolic images for imagination. Environmental biologist Hardin advocated asking 'and then what' questions to detect unexpected consequences of focusing too intently on a single goal (e.g. economic development or exponential growth). ${ }^{1}$

\section{OBSTACLES TO TRANSDISCIPLINARITY}

Remarkable progress has been made in overcoming the obstacles to transdisciplinary activities in the over 55 years I have been engaged in these activities. Both individuals and disciplines have experienced intellectual and financial benefits from this progress. Wilson (1998) believes this trend is irreversible and provides persuasive evidence to support his view. The major issue now rests on whether the rate of change will be adequate to enable humankind to have the information essential to achieve sustainable use of the planet. Unsustainable practices are still the norm, and natural capital is being depleted at a rate far in excess of its regeneration.

Most collaborations are still interdisciplinary and typically involve only two disciplines. Interdisciplinary is the appropriate term since the boundaries of the disciplines are quite evident, but the goal requires the participation of both. A major effort should be made toward synthesis of all phases of the relationship. This design is a distinct improvement over multidisciplinary studies in which each discipline has a separate approach toward a common goal, with synthesis or a series of feedback loops between or among the disciplines, so that information generated in bears only token influence on the activities of the others. Transdisciplinary activities require that the research or problem-solving design not be dominated by the disciplines, that robust synthesis be a major goal, that disciplinary jargon be absent or kept to a minimum, that communication between and among the disciplines be sufficiently effective so that mid-course corrections can be made in all components because of information generated by others, and that the results be comprehensible to reasonably intelligent laypersons.

\section{JOURNALS AND THE COEVOLUTIONARY PROCESS}

A major contribution to this co-evolutionary process could come from journals that aspire to be truly transdisciplinary. These journals would provide an opportunity for transdisciplinary groups to publish their concepts and information without being hampered by the detailed knowledge base and complicated terminology essential to specialized journals. At the same time, transdisciplinary journals must adhere to rigorous quality control measures comparable to specialized journals. This undertaking is indeed a formidable task.

\footnotetext{
${ }^{1}$ See www.garretthardinsociety.org/info/quotes.html
} 
An important feature of producing these journals is the avoidance of endless repetition of information essential to understanding transdisciplinary papers so that the primary message of the manuscript is unmistakable. For example, the field of ethics comprises many subdivisions of great interest to ethicists but that are not essential to a manuscript for which a dictionary definition of ethics is adequate. Meeting the disciplinary requirements of a specialized journal on ethics is not appropriate for a transdisciplinary journal and may hamper communication with non-specialists.

Sustainability has or should have a wide variety of information inputs. Most will be incomplete and some will be contradictory (e.g. as in the ecology/economics debate) and ambiguous. Regrettably, some data may be false (e.g. when prepared by a narrow-minded special interest group). Many people and a wide variety of special interest groups think sequentially (i.e. one item at a time), even when considering a multivariate issue covering large spatial and temporal spans. Results, especially in difficult international situations, may be presented as robust when they have not been confirmed or validated. Even when the data have been demonstrated to be either false or highly uncertain, humankind may be locked into an inappropriate course of action based on unreliable information. However, the human brain does not have predispositions resulting from biological evolution (Ehrlich 2000). Ehrlich (2000) notes that social evolution is important for the human species. Social evolution can be quite rapid while human biological evolution is comparatively slow. Transdisciplinary journals cannot solve this problem, but they can make readers aware of it. Each person only knows a tiny portion of the requirements for living sustainably, but is often too certain that the respective knowledge base is both correct and important.

\section{REASON AWAKE REVISITED}

In the foreword of Reason Awake, Dubos (1970, p. xiii) stated

. . . all ecological systems, whether man-made or natural, must in the long run achieve a state of equilibrium and be self-regenerating with regard to both energy and materials. The ecology of highly industrialized nations has been in a state of disequilibrium for several decades. Furthermore, ecological instability is increasing at such an accelerated rate that disasters are inevitable if the trend continues.

People in denial in affluent countries will protest that Dubos was wrong - there is food in their stores, comfortable shelter, one or more automobiles in the garage, large television sets, at least one personal com- puter, and cell phones for every member of the family. At least two-thirds of the people on the planet would disagree with this complacent viewpoint.

If humankind ever achieves sustainable use of the planet, it will be the result of effective broad communication of the rationale and values essential to success. Arguably, the first step in this process will be to establish the scientific and ethical framework in transdisciplinary journals with a broad readership both geographically and professionally. The second step will require effective communication with the general public. Both will require a minimum of professional jargon and a willingness of participants to invest significant amounts of time in order to cope with the synthesis of many interactive components.

Most transdisciplinary, peer-reviewed journals are comparatively new; all new journals have three interrelated problems: (1) attracting authors with wellestablished reputations, (2) maintaining quality control via knowledgeable reviewers, editorial staff, and editorial board, and (3) obtaining an appropriate readership. Most transdisciplinary authors learned early in their careers that disciplinary publications were the fastest way to establish a professional reputation. The least aggravating means of publishing is in the disciplinary journals in which the reviewers and authors share a substantial knowledge base. However, reputations of some mid- and late-career individuals have been enhanced by transdisciplinary publications. Even so, a disciplinary orientation is the norm for both authors and reviewers for transdisciplinary journals. However, they are usually not from the same discipline and do not share a large knowledge base, including terminology.

Reaching an agreement on the adequacy of a transdisciplinary manuscript is not easy. The author is worried that colleagues in the author's original discipline will accuse him of needless repetition, and reviewers insist on having details that would be unnecessary in a disciplinary journal. This requirement may be beneficial to the readers, especially of a new journal, but authors, reviewers, and readers must develop a more extensive shared knowledge base if the transdisciplinary journal is not cluttered perpetually with basics in a large array of disciplines. In short, a large base of common terminology and concepts would avoid boring regular readers. The large uncertainty is whether the rate of development of a transdisciplinary language will be adequate to cope with the rapidly developing environmental crises. Until these issues are resolved, sustainability will remain an aspiration rather than becoming a reality.

Since the educational system is the primary source of skilled, well-informed professions, what happens in it will have a major impact upon the prospects for achieving sustainable use of the planet. Institutions of 
higher learning are now proud of having a token amount of multidisciplinary and interdisciplinary activities on campus, but are using the word transdisciplinary rarely, if at all. Worse yet, a few educational institutions and individuals believe the terms are interchangeable. An examination of any college or university catalog will demonstrate how discipline-oriented these institutions are. As a caveat, disciplines are essential to educational institutions and sustainable use of the planet. This understanding must be reiterated continually in order to combat the common criticism that transdisciplinarity is hostile to the disciplines.

This academic structure is quite understandable since most educational budgets are allocated by discipline, and transdisciplinary activities are regarded as new programs, which, in an era of tight budgets, usually obtain funds by administrative reallocating of funds from the traditional disciplines. Incidentally, this strategy is often used for start-up funds for activities thought to have a high success rate for obtaining extramural funding.

Almost certainly, some academic institutions will find ways to surmount these obstacles and establish truly transdisciplinary programs devoted to sustainability. Most likely, these will be established with endowment funds and/or special gifts restricted for use for these purposes only. Students of some of these programs will undoubtedly become leaders in transdisciplinary fields, especially those focused on sustainable use of the planet. Since the twenty-first century will be an era of synthesis and integrative science, the graduates of these new transdisciplinary programs should have many employment opportunities not available to those lacking this experience. Additionally, as mentioned before, faculty members who have achieved transdisciplinarity should be very competitive for extramural funding that requires documented transdisciplinary education and experiences.

Since sustainable use of the planet requires both disciplinary and transdisciplinary viewpoints (both topdown and bottom-up sustainability strategies), the isolating mechanisms that kept the disciplines pure must be abolished so that this can take place. As Wilson (1998) noted, this breakdown is already occurring. However the rate may not be adequate to avoid environmental catastrophes during the twenty-first century. As a consequence, this inevitable co-evolution should be accelerated by removing or reducing some of the obstacles to the process. This change has begun in industries and corporations primarily for pragmatic reasons that also espouse a harmonious relationship with natural systems (e.g. Anderson 1998, Natrass \& Altomare 1999).

Allen (2003) envisions an emerging ethnosphere (a planetary system of intercommunication based on a human value system that will produce new patterns of behavior), which might well be one of the keys to sustainable use of the planet. This behavioral change could be a major selective force on the educational system. Business and society should also be powerful forces in making this happen.

Humankind has been the only species that has escaped, at least temporarily, having an intimate survival relationship with local or regional ecosystems (Eldredge 1999). Now, if the relationship becomes a global one as required by the quest for sustainable use of the planet, it is bound by the same constraints of other species - only the temporal and spatial scales differ. This scenario would require a more harmonious relationship between humankind and natural systems that would be co-evolving (i.e. each inextricably linked to the other in such a way that neither can survive in its present form without the other). At one time, if the local tribal (or other) cultures outgrew the carrying capacity of their local or regional ecosystems, excess population could migrate to other areas with a larger carrying capacity. Alternatively, in a technological age, resources could be extracted (e.g. petroleum) or produced elsewhere (e.g. food) and relocated to increase regional carrying capacity. However, in a global society, the technological component of humankind's life support system must be in balance with the ecological component (Cairns 1996). The old strategies used by populations that exceeded carrying capacity - migration and war-are neither suitable nor sustainable for a crowded planet.

\section{REGAINING TRANSDISCIPLINARITY}

Sustainable use of the planet requires that humankind examine natural systems from a dynamic, problem-solving perspective. Humankind still exists because its ancestors sought and used information about natural systems wisely. If posterity is to inherit a habitable world, humankind must interpret signals from the natural world and adjust its behavior so that Earth's ecological life support system is healthy. Humankind's interactions with nature have always been complex. For most of the time humans have been on the planet, there were no disciplines to fragment knowledge about natural systems. Only a comparatively few generations have passed since humans began to live in urban environments with a concomitant dependence upon mechanized technology. Distant ancestors were a small-group species, spread thinly over the landscape and having a minor effect upon it. Now humankind is trying to live in enormous groups, which mostly lack an intimate association with natural systems. Sustainable use of the planet requires that humans regain their holistic perspective of natural systems that they have had for most of the time they have existed on the planet. 


\section{CONCLUSIONS}

Sustainable use of the planet requires a harmonious relationship between disciplinary specialists and transdisciplinary generalists. Despite illusions of humankind's freedom from the laws of nature, humans are just another species subject to all the selective processes that govern the survival and health of other life forms. The goal of sustainability is to achieve a sustainable relationship with natural systems (i.e. natural capital and ecosystem services), which constitute the basic life support system of Homo sapiens and 30+ million other species. Recently, in evolutionary time, humankind has created a technology upon which it is also dependent but which, as operated at present, constitutes the major threat to the integrity of natural systems.

The goal of sustainability is to retain the benefits of technology without endangering the planet's ecological life support system. This goal requires an integration and orchestration of knowledge unprecedented in human history. The nineteenth and twentieth centuries were the age of specialization, which provided a multitude of benefits to humankind without which the present level of population size (over 6 billion and likely to reach 10 billion in the first half of the twenty-first century) and affluence would not be possible. However, technology that uses natural capital at an unsustainable rate threatens the well-being of both present and future generations.

The goal of sustainable use of the planet is to protect and accumulate natural capital so that ecosystem services will be both dependable and abundant. In short, sustainability requires a mutualistic relationship between two complex, dynamic, multidimensional systems - human society and natural systems of which Homo sapiens is a part. Since human society depends upon its educational system to produce citizens capable of a synthesis that will make sustainability possible, society must transform its structure (based on disciplines) so that reductionist science does not threaten or impede development of integrative science. This change must be accomplished rapidly since a resource crisis is likely in the first half of the twenty-first century, even if some remedial measures are taken (e.g. reduction of greenhouse gases), because recovery of natural systems takes time, often decades or longer.

Necessity usually results in new behavior patterns for individuals, new perspectives in government, and changed practices in those industries and corporations anxious to have a long-term market. Globalization creates problems but also opportunities for solutions. The global Internet provides both information and commu-

Editorial responsibility: David R. Orvos, $\mathrm{PhD}$ (Editor), Sweet Briar, VA, USA nication opportunities unprecedented in human history. Sustainable use of the planet will, if successful, represent a superb opportunity for humankind to cast off counter-productive unsustainable practices. This historic endeavor provides a wonderful opportunity to have a beneficial effect upon the future, which should produce great satisfaction even though the participants will not live to see it. I believe Ethics in Science and Environmental Politics has an opportunity to make a major contribution to this paradigm shift, which will represent a defining moment in human history. Due to globalization, survival, which has required a holistic perspective for most of human history, is more important now than ever.

Acknowledgements. K Cairns transferred the handwritten draft to the word processor. D Donald provided editorial assistance.

\section{LITERATURE CITED}

Allen J (2003) Ethnospherics. ESEP 2003:7-24

Almeida SP, Case SK, Fournier JM, Fugii H, Cairns J Jr, Dickson KL, Pryfogle P (1978) Analysis of algae samples using coherent optical processing. In: Proceedings of the International Commission for Optics, ICO-11, Madrid, Spain, pp 351-354

Anderson RC (1998) Mid-course correction: toward a sustainable enterprise: the interface model. Chelsea Green Publishing Co, White River Junction, VT

Boulding KE (1956) The image. University of Michigan Press, Ann Arbor, MI

Cairns J Jr (1996) Determining the balance between technological and ecosystem services. In: Schulze PC (ed) Engineering within ecological constraints. National Academy Press, Washington, DC, pp 13-30

Cairns J Jr, Dickson KL, Slocomb JP, Almeida SP, Eu KHT (1976) Automated pollution monitoring with microcosms. Int J Environ Stud 10:43-49

Dubos R (1970) Reason awake. Columbia University Press, New York

Ehrlich PR (2000) Human natures. Island Press, Washington, DC

Eldredge N (1999) The pattern of evolution. WH Freeman and Company, New York

Heerwagen JH, Orians GH (1993) Humans, habitats and aesthetics. In: Kellert SR, Wilson EO (eds) The biophilia hypothesis. Island Press, Washington, DC, p 138-172

Lovelock J (2000) Preface. In: The ages of Gaia: a biography of our living Earth. Oxford University Press, Oxford, UK

Natrass B, Altomare M (1999) The natural step for business. New Society Publishers, Gabriola Island, British Columbia

Norton BG (2003) Searching for sustainability. Cambridge University Press, Cambridge, UK

Szent-Gyorgi A (1962) The persistence of the caveman. Sat Rev 7July:11

Wilson EO (1998) Consilience: the unity of knowledge. Random House, New York

Submitted: February 4, 2004; Accepted: May 13, 2004

Proofs received from author(s): May 19, 2004

Published on the web: May 24, 2004 